\title{
An Evaluation of Foundation Provisioning Curriculum Delivery Workshops for Enabling Epistemological Access
}

\author{
Dr. Vuyisile Nkonki
}

University of Fort Hare Email: vnkonki@ufh.ac.za

\section{Ms. Siyanda Ntlabathi}

University of Fort Hare Email: sntlabathi@ufh.ac.za

\section{Doi:10.5901/mjss.2014.v5n11p109}

\section{Abstract}

The issue about how to enable Foundation Provisioning lecturers to design and deliver curriculum for underprepared students that would enable them to access disciplinary epistemologies and succeed in their programmes of study is the focus of this paper. It argues that the curriculum is a point of leverage in terms of enabling epistemological access, embedding graduateness and academic literacies, foster engagement in active, collaborative, and self-regulated learning in foundation provisioning. Framed in the interpretive perspective, this case study research used various Scholarship of Curriculum Practice (SoCP) frameworks to reflect on Foundation Provisioning curriculum development interventions offered by academic developers of the Teaching and Learning Centre in an institution of Higher Learning. The curriculum development workshops were used as cases for this study which focused on the infusion of academic literacies, alignment of curricular to specific level descriptors, integration of technology to enhance teaching and learning, assessment in the Foundation provisioning context, the development and strategic use of the Foundation Provisioning learning guides. Data was obtained from a total of forty (40) Foundation Provisioning lecturers who were involved in the workshops. An evaluation questionnaire which consisted of open questions and a rating scale was used to solicit participants' views on the benefits of the curriculum development workshops, dispositions to act on the insights gained, and areas where improvements in the Foundation curriculum are sought. Qualitative data were analysed thematically, and a rating scale was used gauge the overall benefits of the workshop. The research findings report on the benefits of using the epistemological access construct, and the curriculum frameworks as theoretical tools for reflecting on foundation provisioning activities and outcomes, and areas of foundation provision practice where these are applicable, as well as areas where improvement and further development of teaching and learning practices are sought. The study concludes that there is need for the fore-grounding of lecturers on the curriculum frameworks that underlie foundation provisioning, and the capacitation on how to embed knowledge literacies in the foundation curriculum. Recommendations for foundation curriculum alignment in the form of adjustments to the module learning guides and the strategic use of these learning guides to foster learning are made. The need to plan and embed in the actual curriculum delivery, tracking, active learning, and other foundation literacies is recommended.

Keywords: Curriculum delivery, Foundation Provisioning, Scholarship of Curriculum Practice, epistemological access, academic development

\section{Introduction and Background}

Foundation Provision was developed in order to enable formal access to underprepared students who, with more learning opportunities and additional support have the potential to succeed. Though the requirements for Foundation Provisioning students are differentiated at the entry point compared to those of mainstream students, there is an expectation of equity of outcomes at the exit point of the programme. As a strategy to improve student success and throughput rates in South African higher education institutions, Foundation Provisioning aims to ensure that these underprepared students succeed and achieve the same academic achievement levels at the exit point as their mainstream counterparts. Foundation Provisioning aims at addressing the articulation gap in the first year of study, lays a solid foundation that enables epistemological access, thus ensuring academic success and improvement of throughputs (Scott, Yeld, and Henry, 2007; Boughey, 2005; Strydom, Mentz, and Kuhn, 2010). The Department of Education (2001) defines Foundation provisioning as the offering of modules, courses, or other curricular elements that are intended to equip underprepared students to cope with the demands of mainstream academic programmes. This definition impresses the need to approach foundation 
curriculum design and delivery differently from that of mainstream since Foundation Provisioning has a formative and developmental focus. Accessing formally the corridors of a university is not enough, though. Once admitted, students face the challenge of accessing disciplinary knowledge and ways of knowing the discipline known as 'epistemological access'. The question for academic development is how to equip foundation provisioning lecturers so that they enable epistemological access on the part of their students.

The term 'epistemological access' is a theoretical construct first used by Morrow in his argument about what students are entitled to, in the curriculum delivery processes (Young, 2012). Following the introduction of Foundation Provisioning and extended programmes, the construct has since been used as an organising concept, as well as an outcome, for all the foundation provisioning activities. In line with Morrow's argument about "epistemological access" as what students are entitled to, Young (2012) agrees and further asserts that the social and educational justice imperative is a curriculum principle that should be assured to all students irrespective of whether they are foundation or mainstream students. Frith and Lloyd (2013) allude to epistemological access in their reference to access to the academic practices and knowledge of the academic disciplines. It also means access into the key concepts and procedures of an academic discipline and to the ways of knowing of that discipline. Epistemological access is according to Boughey (2005) involving negotiation and mediation, as well as making overt disciplinary rules and conventions that determine what count as knowledge. These ideas resonate well with Northedge's (2003) idea of teachers as subject experts whose task is to unlock disciplinary codes, unspoken assumptions, rules, structures, processes, implicit questions, frames of reference, et cetera, so as to expose and explicate the essential simplicity of the ideas hidden beneath the disciplinary codes. Epistemological access is also related to Northedge's (2003) idea of enabling students to speak the discourse by helping students to express their thoughts using appropriate discipline-specific ways of communicating and expressing thoughts. In a similar vein, Frith and Lloyd (2013) argue that epistemological access aims at making implicit academic practices and underlying knowledge systems more explicit.

Related to the above epistemological access imperative is the idea of developing self regulated learning competencies on the part of the foundation provisioning students so that they can manage, monitor, control and regulate their learning by setting up goals which are crystallised in standards, criteria, and specific targets (Nicol and Mcfarlane, 2006). Self-regulated learning also involves harnessing cognitive, affective, motivational, volitional, and behavioural aspects of learning. This would include exertion of effort, management and deployment of learning resources, task engagement, students' understanding, reactions, and responsiveness to the lecturer's feedback. In line with the selfregulated learning imperative we argue that students' engagement with educationally purposive activities would be evidence of epistemological access, and therefore, propose curriculum delivery interventions for foundation provisioning lecturers that would help them to promote the engagement of foundation students. In our view, the engagement benchmarks, namely: level of academic challenge, active collaborative learning, students-staff interaction, and enriching educational experiences (Strydom and Mentz, 2010) should foster epistemological access. If self-regulated learning and engagement capacities are to be developed and fostered on the part of foundation students, there needs to be a reconsideration of how foundation curriculum delivery is approached.

The under-preparedness of students as a result of the poor schooling system that many of the students go through, as well as the under-preparedness of lecturers to deal with the challenges that foundation students manifest, mandate that curriculum delivery in foundation provisioning be done differently from mainstream teaching. Lotz-Sisitka (2009) argues that epistemological access is constrained by teaching practices if sophisticated approaches are not used to mediate between abstract and concrete, as well as between situated activity and discipline-specific concepts. She further argues that teaching practices limit the scope and the level of epistemological access if inadequate attention is paid to normative expectations related to knowledge structures and curricular standards. We believe that lack of understanding about how teaching and learning should be approached in the context of foundation provisioning has led to ad hoc decisions about adding, modifying, or tinkering with individual course offerings. It has been observed that others continue with the business as usual lecturing approaches without due consideration of how their teaching practices bear on epistemological access. It is against this background that we felt the need for a change of approach in the manner in which foundation provisioning curriculum delivery is conceived and approached.

In order for academic development practitioners to advise, support, develop and inform interventions that would help foundation provision practitioners approach their teaching in a manner that enables their students to gain epistemological access, engage, and self-regulate their own learning, various curriculum frameworks that have a bearing on foundation provisioning and epistemological access had to be considered and used to foreground the foundation curriculum delivery interventions. 


\section{Curriculum Design and Delivery Frameworks}

Curriculum specialists have pondered over the issue of curriculum design and delivery that enables epistemological access. In this paper we draw on a number of frameworks to show how these can be used to enable epistemological access in the foundation provisioning context.

\subsection{Threshold Concepts Theory}

Frith and Lloyd (2013) used the threshold concepts framework as a means of achieving epistemological access to a discipline or practice, and as a framework for providing an approach to evaluating aspects of the success or failure of curriculum interventions aimed at promoting epistemological access. They argue that threshold concepts are a gateway to thinking, acting, and communicating authentically in a particular discourse. Threshold concepts are conceptual gateways that aid understanding of previously inaccessible and troublesome ways of thinking about a concept. Meyer and Land (2005) identify key features of threshold concepts as transformational, troublesome, irreversible, integrative, bounded, discursive, reconstitutive, and liminality. They then provide a way of focussing on aspects of the development of students' academic literacy. Threshold concepts lead to a change in perspective which is irreversible and transformative. These authors argue that while most of these threshold concepts are located in the disciplines, some of them are to be found in the realm of academic literacy underlying important disciplinary concepts. The use-value of the threshold concept theoretical framework is according to Meyer and Land (2005) lying in its explanatory potential to locate troublesome aspects of disciplinary knowledge, and to assist lecturers in identifying appropriate ways of modifying or redesigning curricula to enable students to negotiate epistemological transitions, and ontological transformation.

\subsection{Futures of knowledge and knowledgeable action}

Muller (2012) argues that epistemological access allows students access to theoretical propositions and systems, knowledge of empirical facts, and knowledge of practice with its attendant rules, norms, and ways of being and acting. He refers to these as futures of knowledge, and distinguishes them from knowledgeable action. In his typology of futures of knowledge and knowledgeable action, Muller (2012) distinguishes between futures 1, 2 and 3. Future 1 is described as rational, disembodied, and facts-based curriculum in which theory is learnt as facts. He argues that the tendency with future 1 knowledge is rote learning of facts by memorisation. Future 2 is described as practice-based, embodied, and characteristic of skills or outcomes-based curriculum. The critique against future 2 is that theory is shoved to the background and emphasis is placed on the practical applications of learning through emphasis on procedures. Future 3 is described as relational and combines the features of one and two, and involves doing things with knowledge, termed knowledgeable action. As for knowledgeable action, Muller (2012) argues for a focus on "what it means to do things with knowledge" and contends that little is known about how this works, and that this area should be given primacy by academic development practitioners. We believe, as Muller does, that 'doing things with knowledge' should be developed on the part of foundation students, and that foundation lecturers should enable the development of this competence.

\subsection{Learning-centred curricula}

Hubball and Gold (2007) argue for learning-centred curricula that address the learning styles, diverse learning experiences, and curricula that integrate and connect individual course learning experiences, and promote deep learning. These authors argue for learning centred curricula that focuses on contextually bound learning outcomes, and the integration of diverse pedagogies. They further assert that learning outcomes should focus on higher order and integrated abilities. According to Hubball and Burt (2004) a learning-centred curricula emphasises learning communities, curriculum integration, diverse pedagogies and clearly defined learning outcomes. Implementing a learning-centred curriculum requires an integrated approach that combines both pedagogical and organisational change strategies. The integrated learning-centred curricula model combines learning context strategies (support, leadership qualities, teamwork, et cetera); planning strategies (critical and specific learning outcomes); assessment strategies (range of assessment methods and opportunities); and programming strategies (diverse learning strategies: interdisciplinary learning modules, learning technologies, problem-based learning, lectures, independents study, and field experience) that allow students opportunities to acquire, integrate and apply knowledge in diverse settings (Hubball and Gold, 2007; Hubball and Burt, 2004). 


\subsection{T- Curriculum}

Shay (2013) argues that the curriculum is an area where change could be leveraged so that what is at odds in so far as throughputs, completion rates and the quality of graduates is improved. She further argues that curriculum is where outcomes that are valued are intentionally and systematically embedded. She further argues for a "T curriculum" that is characterised by a particular selection and sequencing of what is valued in order to achieve a "T graduate". The horizontal part of the "T" is according to her, denoting outcomes that relate to thinking broadly and could be achieved through courses outside of the major, interdisciplinary courses, extra-curricular learning, and courses meant to tap into ethical and social consciousness. The vertical part of the "T" represents depth of specialisation. The principles that underpin the "T curriculum" are encapsulated in the FREE acronym. The letters in the acronym denote (1) Flexibility at the point of entry, differentiated pathways, with non-negotiable exit standards; (2) Reinforcement for developmental provisioning for creative and innovative ways of thinking; (3) Enhancing the curriculum would mean embedding academic literacies, quantitative, digital, career, and information literacies; (4) Enriched in order to achieve breadth, graduate attributes through such things as ICT integration to develop ICT skills, writing intensive courses for the development of writing skills.

In Foundation Provisioning, we favour the inclusion of academic literacies in the individual modules, by individual lecturers, and suggest that the foundation provisioning module learning guides need to be rethought and redesigned so as to leverage engagement, reinforcement, enhancement, enrichment, and self-regulated learning. We, therefore, advocate for a curriculum delivery model for foundation provisioning that is deep and broad founded on the tenets of the curriculum frameworks outlined above. In a bid to give effect to the foundation curriculum delivery model, curriculum development workshops for foundation provisioning practitioners were developed and conducted with the four Faculties that offer Foundation provisioning in a particular higher education institution.

\section{The Nature of Foundation Curriculum Development Workshops}

The curriculum delivery workshops for the Foundation provisioning lecturers were meant to capacitate them on ways of integrating information and communication technologies to benefit teaching and learning; embedding academic literacies into the teaching and learning practices; enabling epistemological access through the strategic use of assessment to foster learning; and how to design the learning guide so that it serves as a leveraging tool in the reinforcement, enrichment, and enhancement of curriculum delivery of foundation provisioning modules or courses. We believed that the learning guide for foundation provisioning modules should take a learning centred curriculum model approach, and hence our belief in the inclusion of learning context strategies such as learning support structures; the reflection of more assessment opportunities, variety of assessment methods, and explicit assessment criteria. In addition, programming structures such as learning strategies, learning technologies and the possibilities they offer in the enhancement of students learning; and planning strategies such as the level descriptors, learning outcomes and their associated assessment criteria were all part of the curriculum development and delivery workshops for foundation provisioning lecturers. The focus was on how to embed all of the above in the module learning guides.

The infusion of academic literacies into teaching and learning presentation of the workshops focused on the models of academic literacy, and the various ways of infusing the academic literacies in the contents of the modules. It also looked at how 'graduateness' can be enhanced by deliberately and systematically embedding academic literacies in the foundation provisioning modules. This presentation also included a focus on 'writing to learn' high stakes and low stakes approaches, as means of enhancing learning and enabling epistemological access, and how to include these in the learning guide. This presentation also focused on how to use the more learning opportunities afforded to foundation provisioning modules to 'scaffold' learning by 'tiering' tasks. All of the above-mentioned activities were illustrated by means of examples.

The assessment in the context of foundation provision presentation focused on what it means to have more assessment opportunities, and what could be done differently through assessment to enable students to understand and speak disciplinary discourse. Emphasis was placed on the activities during the pre-assessment and post-assessment sessions which should be part of the foundation provisioning curriculum and reflected in the module learning guides. It was emphasised that documents outlining pre-set and explicit criteria should be part of the learning guide, and that these criteria need to be discussed in class for a shared understanding of them. In addition, exemplars of work where these criteria are applied and exhibited should be shared with students during the pre-assessment session. It is also in these pre-assessment sessions that students are asked to model exemplars in their write-ups. The need to provide students with the opportunities to use criteria to judge or review their own and each others' work through self and peer assessment 
in the post assessment sessions was emphasised. Examples of how the above could be actualised were provided.

The Technology enhanced Learning presentation (TeL) focused on the integration of technology to address substantive challenges of teaching and learning, and enhance teaching and learning of foundation provisioning students. Strydom and Mentz (2010) found that using electronic technology to discuss or complete assignments is one of the ways of enriching an educational experience. In line with the institution's mission of 'developing a critical scholarly culture encouraging research-based and context-driven transformative and innovative teaching and learning practices that involve the integration of technology', the presentation featured functionalities on the Blackboard platform that could be used to improve transmission modes of teaching and learning, and those that could be used to promote transactional and transformative modes of learning. Emphasis was placed on using Blackboard to mitigate the challenges posed by large classes, and on using the platform to promote self-regulated learning of the part of foundation students.

The learning guide presentation was meant to bring out the idea that the learning guide leverages curriculum delivery that enables epistemological access. We hold the view that transforming curriculum delivery at programme level involves changes in the design and strategic use of the learning guide. This workshop presentation focused on the ordering and sequencing of learning activities associated with the delivery of the individual curriculum modules. It emphasised the need to articulate explicitly curricular standards, the exposition and explication of the generic level descriptors and their translation into module-specific subject descriptors, as well as the spelling out of the criteria by which module outcomes are to be assessed. The role of the Bloom's taxonomy in the specification of standards and expectations, and the level of academic challenge (Strydom and Mentz, 2010) in the pitching of learning activities was emphasised. Participants were alerted to the mental processing skills involved in the action verbs suggested by the Blooms taxonomy. The learning guide template was shared with the foundation provisioning practitioners. The purpose of designing and developing a learning guide, and the strategic use of the learning guide such that it helps students access the discipline, navigate their way through the disciplinary discourses, and self-regulate their learning, was highlighted.

\section{Research Questions}

1. How did foundation lecturers and co-ordinators evaluate the foundation provisioning curriculum delivery workshops for epistemological access?

2. What could be done to improve and further develop foundation provisioning curriculum delivery for epistemological access?

\section{Aim of Study}

The study aimed at evaluating the benefits, excellent aspects, as well as areas of improvement and further development in the foundation curriculum delivery workshops for epistemological access.

\section{Methodology}

\subsection{Research Paradigm}

The evaluation of the curriculum development workshops for foundation provisioning employed the interpretive perspective to discern foundation provisioning lecturers' understandings, reflections, meanings and reflections on their practices based on the insights gained from the foundation provisioning workshops. Neuman (1997) posits that participants' subjective world views shape how they act. This research concerned itself with foundation lecturers' responses to the workshops and their dispositions to act on the insights gained. Cohen, Manion and Lawrence (2007) argue that the interpretive perspective helps to ascertain the intentions of actors and as such future oriented. Thus, the interpretive perspective was deemed relevant for thus study since the purpose of the foundation workshops was to get lectures was to get lecturers to reconsider their curriculum delivery strategies for foundation provisioning in the light of the grounded curriculum frameworks.

\subsection{Research Design}

The study adopted a case study design in which foundation provisioning workshop interventions were a case. Leedy and Ormrod (2005) define a case as an individual, programme, event or intervention which can promote understanding or inform practice for similar situations. The case study allows for the interrogation of documents and other extensive data 
on the programme or event on which the investigation is focused. It also allows for the use of self reports from interviews and scores from rating scales. Qualitative research questions were the main questions augmented by a quantitative rating scale.

\subsection{Population and sampling}

A purposive sample of forty (40) foundation provisioning lecturers and co-ordinators who were both attendees and participants of the workshops from four (4) faculties that offer foundation provisioning constituted the sample.

\subsection{Data Analysis}

Data from the open-ended questions were qualitatively analysed to discern recurring meaning units. These were later aggregated into emerging themes. The satisfaction index of the workshops was calculated from the workshop ratings by the workshop participants. The scale's ratings were 4 (excellent), 3 (good), 2 (average), and 1 (poor).

\section{Results of the Evaluation of the Curriculum Delivery Workshops for Foundation Provisioning}

The participants of the workshop were asked to reflect on the worth of the curriculum delivery workshops, highlight where change of practice would be effected, and point out areas where follow up workshops for further development of practice would be needed.

\subsection{Dispositions to act on the insights gained}

The sentiments below were echoed by the workshop participants as an indication of their dispositions to act on the insights gained from the curriculum delivery workshop. A lot of points were highlighted on the "integration of new methods of assessment" in a bid to change the way students learn, and on "allowing more opportunities for assessment" so that foundation lecturers get the students to practice exercises on the outcomes they are expected to achieve. Another notable insight was that of "setting up assessment rubric with specific criteria" as well as the use of "different assessment techniques to improve teaching and learning". The other area where change of practice is sought concerned "interaction with students in a participatory manner as opposed to outright lecturing". Participation is an indication of engagement with the learning task at hand which needs to be enabled by the lecturer through organisation, ordering and sequencing of the learning activities. In terms of enabling epistemological access one of the workshop participants remarked "I will use a lot of scaffolding and assessment techniques to improve my teaching and learning". This sentiment appraises the assistance and support needed by foundation students if success is to be achieved. With respect to the exposition and explication of disciplinary codes, the "I will be more adamant about setting up assessment rubrics with specific criteria" statement is an appreciation of the explicit specification of criteria by which foundation students' work is assessed. Other sentiments expressed about the "application of teaching methods that involve students in order to develop their independence" were in appreciation and appraisal of the engagement and self-regulated learning competencies that were emphasised as needing development on the part of foundation students.

\subsection{Areas of success in the curriculum development workshops for foundation provisioning}

The participants of the workshop felt that the topics of the workshop linked directly to their professional practice. The curriculum development workshops were given a $93 \%$ satisfaction rating by the participants. One of the participants of the workshops commented that the curriculum delivery for foundation provisioning workshops was "eye-opening and transformative". The areas outlined below were indicated as benefits as well as success areas of the curriculum delivery for foundation provisioning workshops. These successes need to be strengthened and consolidated. The responses of the participants were organised and categorised into themes. The most dominant benefit as expressed by the number of sentiments involved the incorporation of technology into teaching and learning. The design and development of the learning guide was also thought to be one of the most informative presentations. Other areas that are appraised as worthy and useful included understanding students' needs and ways of accommodating students' learning styles. Others included the altering of teaching strategies so as to promote active learning. Other sentiments expressed were around the provision of more assessment opportunities and a variation of assessment tasks as critical in re-orienting students' learning patterns, and the fostering of deep and meaningful learning. 


\subsection{Aspects of Curriculum Development workshops for foundation provisioning needing attention}

The aspects outlined below were indicated as areas where follow up workshops and further capacity development is needed for curriculum delivery in the context of foundation provisioning so as to enable epistemological access. The "infusion of academic literacy into teaching practices" was indicated by many as an area where further development and improvement of practice by foundation provisioning practitioners is needed. Another aspect that still needs follow up intervention was identified as the use of "active learning in large classes" even though the workshop's specific focus was not on large classes. Reflecting on the learning guide presentation and its emphasis on aligning teaching and assessment to the appropriate NQF levels, one of the participants felt the need for further engagement with "the practice of using NQF levels when preparing lecture presentations and assessments" so as to ensure that the foundation provisioning modules are pitched appropriately, and that they are neither below nor above the national threshold standards. Other participants pondered on using different types of technologies to enhance teaching and promote transactional learning through exchanges, conversations in online-discussions, and expressed the need for more capacity development in that regard. The "tracking of students' performance" at module and programme levels was indicated as key by some of the participants in terms of enabling epistemological access. The teaching methods for reaching out to low performing students and improving students' attendance was indicated as another area that need focused attention in the stretching and embedding of foundation curriculum that would enable epistemological access.

\section{Discussion}

The 'epistemological access' principle which underlies the teaching approaches for foundation students, was suggested as an organising concept in the curriculum delivery workshops because of its value-fit and credence in quite a number of the curriculum delivery frameworks reviewed, namely: integrated learning-centred framework, threshold concepts theory, knowledge futures, and FREE curriculum delivery models (Hubball and Gold, 2007; Meyer and Land, 2005; Muller, 2012; and Shay, 2013). Its transformative potential can be seen from the lecturers' dispositions to act on the insights gained, and the indication of areas where changes in lecturers' practices are sought. These are indications of shift in perspective and reconsiderations of their curriculum delivery practices on the part of foundation provisioning practitioners, which should be followed-up for support and further capacity development by academic development practitioners working with foundation provisioning lecturers. The various ways of involving students and developing independence on the part of the foundation students which are commended by the workshop participants as beneficial find confirmation and approval in the engagement and self-regulated learning scholarly works (Strydom and Mentz, 2010; Nicol and Mcfarlane, 2006). The expressed need on the teaching methods to reach low performing students could be addressed by a careful consideration of the threshold concepts approach as a lens for reflecting on troublesome content knowledge (Frith and Lloyd, 2013). The threshold concepts theory challenges the way lecturers think and teach problematic disciplinary content knowledge and should prove useful in unlocking and explicating disciplinary knowledge so that epistemological access is enabled. The learning-centred and curriculum integration framework of Hubball and Gold (2007) surely inform the curriculum intervention that seek to embed literacies, enrich and enhance the learning experiences that would enable foundation students not only to gain epistemological access but to enable their success in the disciplinary areas of their choice.

\section{Conclusions}

We conclude that the importance of considering curriculum delivery frameworks when planning curriculum delivery workshops for foundation provisioning is strengthened by the findings of this particular study. These frameworks provide ideas on how to stretch modules, embed literacies and foster generic scholarly competencies as well as disciplinespecific ways of behaving as learners on the part of the students. The findings of this study sensitised foundation practitioners and the academic development practitioners in the foundation provisioning pivot to the importance of holding ongoing curriculum delivery workshops that are fore-grounded on a curriculum theoretical-conceptual framework, that is, epistemological access. Such a theoretical construct not only guides and directs curriculum delivery activities (means), but also provide curriculum deliverers with a value to aim towards (ends), whilst providing measures of attainment of that value outcome. The need to conduct curriculum delivery workshops in the beginning of the academic year, or, at the end of the year preceding the delivery of the curriculum so as to inform planning by foundation provisioning practitioners was expressed. Our view that foundation curriculum delivery changes are leveraged in the learning guide was practicalised in the curriculum delivery workshops with examples of how to integrate technology, infuse academic literacies, use 
assessment strategically to develop and re-orient students' engagement with learning so that they regulate their own learning. Again, issues pertaining to appropriate pitching of modules using level descriptors and assessment criteria were emphasised and fore-grounded in the curriculum frameworks.

\section{Recommendations}

Based on the foregoing conclusions, we recommend that Foundation Provisioning co-ordinators, both in the Academic Development centre and the Faculties, should ensure that teaching and learning in the Foundation Provisioning context is enhanced, reinforced, and enriched. The module learning guides should spell out explicitly the knowledge arts, and the mental processing skills that have a bearing on the learning of a particular content, and how these are to be addressed by the lecturer and the students. Academic Development (AD) practitioners should work closely with the foundation practitioners towards ensuring that their learning guides are used strategically to ensure epistemological access, foster the development of academic literacies, and ensure academic success. Again, the need to plan and embed in the actual curriculum delivery, the tracking of students' performance, active learning in large classes, as well as reaching out to low performing students need to be an integral part of the curriculum delivery processes for foundation provisioning rather than these being thought-after, separate and detached interventions.

\section{References}

Boughey, C. (2005). Epistemological Access to the university: An Alternative perspective. South African Journal of Higher Education, 19 (3), 638-650.

Cohen, L., Manion, L., \& Morrison, K. ( 2007). Research Methods in Education, (6 th ed.). London. Routledge Taylor and Francis Group.

Frith, V., \& Lloyd, P. (2013). Quantitative Literacy and Epistemological Access at University: Reflections on using the Threshold Concepts Framework for Research. Proceedings of the Seventh International Mathematics Education and Society Conference, 2, 272-281.

Hubball, H., \& Burt, H. (2004). An Integrated Approach to Developing and Implementing Learning-centred Curricula. International Journal for Academic Development, 9 (1), 51-65.

Hubball, H., \& Gold, N. (2007). the Scholarship of curriculum Practice and Undergraduate Program Reform: Integrating theory into practice. New Directions for Teaching and Learning, 112, 5-14.

Leedy, P.D., \& Ormrod, J.E. (2005). Practical Research: Planning and Design. (8th ed.). New Jersey: Pearson Merrill Prentice Hall.

Lotz-Sisitka, H. (2009). Epistemological access as an open question in education. Journal of Education, 46, 57-80.

Meyer, J.H.F., \& Land, R. (2005). Threshold concepts and troublesome knowledge (2):

Epistemological considerations and a conceptual framework for teaching and learning. Higher Education, 49, 373-388.

Muller, J. (2012). Every picture tells a story: Epistemological access and knowledge, Knowledge and Curriculum in Higher Education Symposium, UCT, 7 \& 8 November 2012.

Neuman, L.W. (1997). Social Research Methods: Qualitative and Quantitative Approaches. (3rd ed.). Boston: Allyn and Bacon.

Nicol, D.J., \& Macfarlane-Dick, D. (2006). Formative assessment and self-regulated learning: a model and seven principles of good feedback practice. Studies in Higher Education, 31(2), 199-218.

Northedge, A. (2003). Enabling Participation in Academic Discourse. Teaching in Higher Education, 8 (2), 169-180.

Scott, I., Yeld, N., \& Hendry, J. (2007). Addressing diversity and development in South Africa: Challenges for educational expertise and scholarship. Cape Town: Council on Higher Education for the Improving Teaching and Learning for Success project. Unpublished.

Shay, S. (2013). A Higher Education Curriculum for the 21st Century. A paper presented in the Teaching and Learning Week, 24 July 2013, University of Fort Hare.

Strydom, J. F., Mentz, M., \& Kuh, G. D. (2010). Enhancing success in higher education by measuring student engagement in South Africa. Acta Academica.

Strydom, J.F., \& Mentz, M. (2010). South African Survey of Student Engagement: Focusing the Student Experience on Success through Student Engagement. Council on Higher Education: Pretoria.

Young, M. (2012). The Curriculum - 'An entitlement to powerful knowledge': A response to John White. [Online] Available: http://www.newvisionsforeducation.org.uk/2012/05/03/the-curriculum-\%E2\%80\%98an-entitlement-to-powerfulknowledge\%E2\%80\%99-a-response-to-john-white/. (September 2, 2013). 